\title{
Gepiekt und gestochen
}

\section{Bernhard Gurtner}

Geschick bei der Blutentnahme kann das ärztliche und pflegerische Prestige wesentlich steigern.

1 Malzev W. Venenpunktion: Tips \& Tricks, Punktion «schlechter Venen» und viel mehr. http:// venpunktion.de (33 Seiten).

Korrespondenz:

Dr. med. Bernhard Gurtner

Eggstrasse 76

CH-8620 Wetzikon

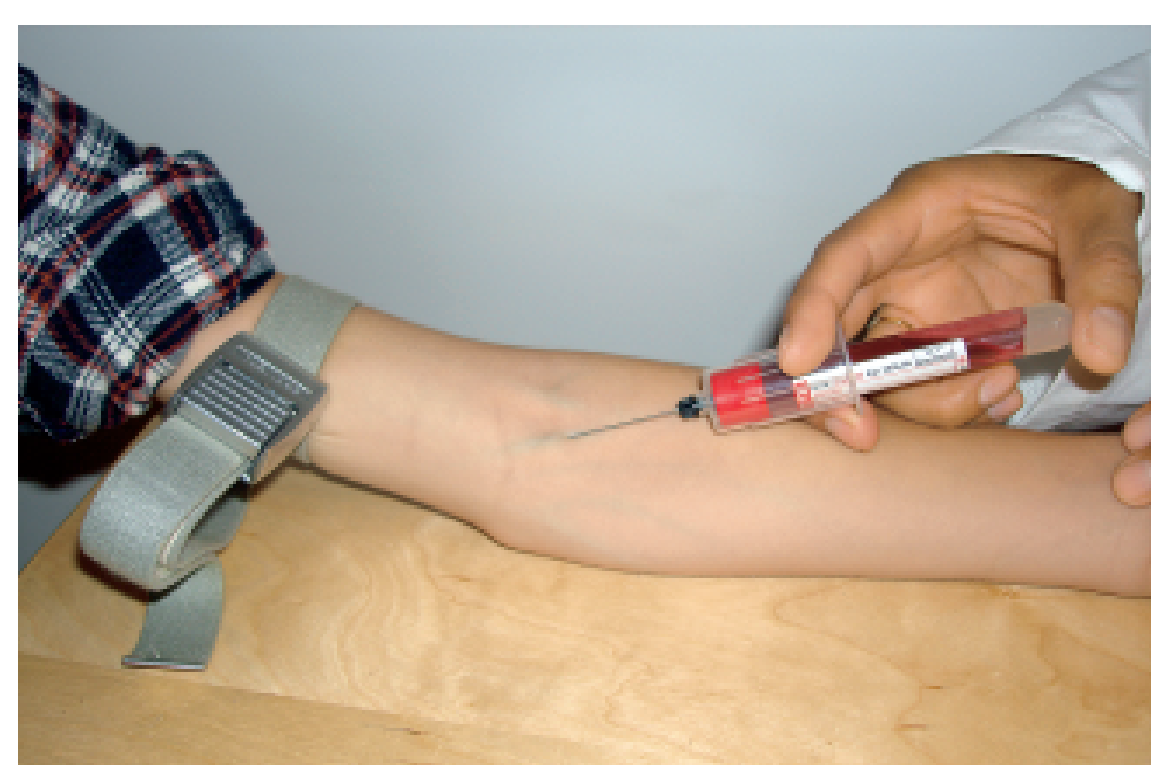

Blutentnahmen, intravenöse Injektionen und Infusionen werden trotz alläglicher Routine immer wieder von Irritationen begleitet. Nicht nur die angestochenen Gefässe können gereizt reagieren, auch die Nerven geplagter Patienten oder frustrierter medizinischer Leitungsmonteure liegen blank, wenn die Übung mehrmals wiederholt oder gar abgebrochen werden muss. «Sie können gut stechen», ist ein Gütesiegel erster Klasse, das dankbare Patienten einer Praxis oder Klinik verleihen, während unliebsame Erfahrun- gen und hässliche Hämatome dem professionellen Prestige erheblichen Schaden zufügen. In vorsichtigen Betrieben gilt deshalb die Hausregel, dass nach zwei misslungenen Versuchen erfolgversprechende Hilfe beizuziehen ist.

Glücklich, wer als Medizinstudent durch eine erfahrene Krankenschwester oder einen geduldigen ärztlichen Berater in die Kunst der Venenpunktion eingeführt wurde und sich nicht durch Versuch und Irrtum - immer auf Kosten der Patienten - an die wahre Meisterschaft herantasten musste. Wir bewunderten eine geschickte Laborantin, wie sie mit Daumen und Zeigefinger der linken Hand die eingeführte Punktionsnadel fixierte und gleichzeitig mit dem abgespreizten Ringfinger die Vene komprimierte, wenn sie die Entnahmeröhrchen wechselte. Instruktive Lehrmittel zu diesem etwas unterschätzten Thema gab es kaum, zahlreich waren aber die Tips der Könner: Das beschwörende Beklopfen der subkutanen Fettschichten brachte nicht viel, es wirkte wohl eher als aufmunterndes Tätscheln. Effektvoller war der Trick des postischämischen Blutandrangs durch erst straffes, dann gelockertes Anlegen der Staubinde. Für ängstliche Anfänger nützlich war auch der Hinweis, die Haut und das Blutgefäss mit einem energischen Ruck-Zuck anzustechen, anstatt sie übervorsichtig einzudellen oder wegzuschieben. Wir lernten, dass es falsch war, die Punktionsstelle nach der Prozedur sogleich mit einem Pflästerchen zu bedecken, wir mussten mindestens zwei Minuten lang manuell komprimieren - bei Antikoagulierten fünf Minuten -, fanden so die Zeit für ein kurzes Gespräch und verhinderten, dass sich auch nach perfekt gelungenen Blutentnahmen oder Injektionen ein Sekundärhämatom bildete. Widersprüchlich waren und sind die Meinungen, wie die Nadelspitze bei der Punktion auszurichten sei. Die Wandläsion und die Gefahr, dass der Anstich zum Durchstich wird, scheinen geringer, wenn die vordere Nadelöffnung nach unten und somit die Schneidekante zum Gefäss hin gewendet wird [1].

Die Älteren unter uns erinnern sich an die robusten Rekordspritzen, die in den Sanitätskisten und Krankenzimmern der Schweizer Armee überlebten, als die zivile Praxis schon lange nur noch Einwegmaterialien benützte. Zuvor mussten die wiederverwendbaren Injektionsnadeln auf einem Bimsstein nachgeschliffen und mit einer streifenden Fingerbewegung auf Widerhaken an der Spitze abgetastet werden. Zusammen mit der in mehrere Teile zerlegten Spritze wurden sie im Autoklaven sterilisiert oder in einem übersprudelnden Kochgefäss reingesotten. Hatte der Glaszylinder nicht schon im heissen Bad einen Sprung erlitten, knackte es nicht selten beim Wiedereinführen des Spritzenstempels, wenn der noch warm geschwollene Metallkolben die zerbrechliche Wandung überdehnte.

Welch ein Fortschritt, als die leichtgängigen, nur einmal zu gebrauchenden Plastikspritzen und die scharfspitzigen Injektionsnadeln mit den kennzeichnenden farbigen Ansätzen aufkamen, die kleine Blaue für das Feingeschäft, die Braune für das Gröbere und die lange Gelbe für Tiefgründiges. Noch grösser war unsere Begeiste- 
rung, als intravenöse Verweilkatheter nicht mehr durch kleinchirurgische «venae sectio» plaziert, sondern perkutan eingeschoben werden konnten. Wir lernten, die V. subclavia erst von oben, dann unter dem Schlüsselbein hindurch zu punktieren, fühlten uns nach den ersten gelungenen Eingriffen als grosse Könner, mussten aber erfahren, dass auch wir (und unsere Patienten!) vor Fehlversuchen oder iatrogenen Komplikationen nicht verschont blieben.

Die ersten Intracaths hatten ihre Kinderkrankheiten, wurden doch Chargen mit Kaliberschwankungen geliefert, so dass die Katheter nach anfänglich glattem Durchschlüpfen in den Führungskanülen steckenblieben, was dazu zwang, das Set als Ganzes wieder zu entfernen, um keine Katheterembolien durch Abscherung zu riskieren. Das Problem erinnerte an den Film «Modern Times» von Charlie Chaplin, der durch ungeschickte Manipulationen an einer Plastikschlauchmaschine groteske Riesenschlangen mit stets wechselndem Umfang erzeugte, so als hätten sie Kaninchen verschluckt. Die englische
Herstellerin der Verweilkatheter bestritt heftig, dass bei ihr ein ähnlicher Produktionsfehler erfolgt war. Sie konnte uns aber weder überhöhte Temperaturen im Materiallager noch ein quetschendes Anpacken beim Auspacken oder Einschieben nachweisen, wie sie es den helvetischen Kraftmenschen zugetraut hätte. Eine Delegation der Firma kam zu guter Letzt für einen Augenschein in die Schweiz und nahm die von zarten Händen angesammelten Fehlgebilde zum Austausch mit. Inskünftig respektierte man uns als schwierige Kunden.

Darauf gab es in rascher Folge stets raffiniertere Verweilkanülen, Führungsdrähte, Infusionsportale und Blutentnahmesysteme. Es kamen aber auch immer mehr drogenabhängige Fixer, bei denen alle oberflächlichen Venen undurchgängig geworden waren, nicht nur an den Extremitäten, sondern auch am Hals und sogar am Penis. Geschützt mit Latexhandschuhen stocherten wir nach tiefliegenden Gefässen, ohne damit je die Quellen des Elends aufzufinden. 